hospital infection which was brought about by contaminated pharmacy "distilled water."

At a London teaching hospital there were 14 new cases of $P s$ aeruginosa respiratory tract infections in August 1968 compared with four or les new cases in each previous month. Nearly all the new cases in previous months were in the intensive care unit but in August there were many cases also on different wards on various floors of the hospital. Several respirators and tracheostomy humidifier were contaminated with Ps aeruginosa, sensitive to polymyxin, gentamicin, and carbenicillin, of the same antibiotic sensitivity and pyocine type as the pseudomonas isolated from the sputum of patients. Most of the infected patients had only recently been attached to a respirator or humidifier and other predisposing factors were usually present, including steroid treatment, respiratory tract disease, and broad-spectrum antibiotic therapy. At the time of the outbreak "distilled water" from the pharmacy was used to fill the humidifier sections of the anaesthetic apparatus. Examination of random sample of four bottles of "distilled water" from the pharmacy showed that all the bottles were heavily contaminated with $P S$ aeruginosa of the same antibiotic sensitivity and pyocine type as that isolated from patients. The plastic bottles which contained the water were also found to be heavily contaminated on their return from the wards. Empty bottles were not sterilised but refilled with "distilled water" in the pharmacy and sent out to the wards. Water collected from a tracheostomy humidifier just before its attachment to one patien yielded growth of the epidemic strain of $P$ aeruginosa and two days later an identical pseudomonas was isolated for the first time from the sputum of the patient. At the end of August all the pharmacy "distilled water" was withdrawn empty plastic bottles disposed of, and only "sterile distilled water" used to fill the humidifier sections of anaesthetic apparatus. In September the number of new $P S$ aeruginosa respiratory infections was reduced to seven and by November the incidence of infection had fallen to four new cases, all in the intensive care unit only.

This outbreak of Ps aeruginosa infections demonstrates the potential hazard to patients of Ps aeruginosa-contaminated pharmacy distilled water. The pharmacy had issued the "distilled water" to the wards without realising the purpose for which it was being used. Many doctors, including anaesthetists, and also nursing staff had not understood the importance of using "sterile distilled water" rather than "distilled water" fo use with anaesthetic apparatus. This erro is probably less likely today because of improved education of staff involved with anaesthetic apparatus. Heating elements are included in modern anaesthetic apparatus which pasteurise the water, helping to reduce the risk of contamination. However, the pasteurisation device is not always used properly, particularly in these days of staff shortages and especially on general wards. Therefore there is still a potential hazard to patients from pseudomonas-contaminated water.

\section{C SHANSON}

Department of Medical Microbiology,

The London

SIR,-In their paper on this subject Dr Rosamund $M$ Baird and her colleagues (28 February, p 511) have justly drawn attention to the presence of pseudomonas contamination in topical preparations and disinfectants dispensed from hospital pharmacies. While agreeing with their conclusions that this problem may be partly overcome by strict attention to hygiene, I feel that more positive action could be taken by using antiseptics and disinfectants which are unlikely to be contaminated by pseudomonads. Ethylenediaminetetraacetic acid (EDTA) has been reported $^{1}$ to sensitise Pseudomonas aeruginosa to a range of antibacterial agents-for example polymyxin, benzalkonium chloride, and parachlorometaxylenol (PCMX), and in addition investigations in these laboratories have shown that a mixture of PCMX and EDTA could not be contaminated with Ps aeruginosa by the method of Bassett et al. ${ }^{2}$

In the light of these findings it seems reasonable to suggest that only those antiseptics and disinfectants which have both a broad spectrum of bactericidal activity and are also known to be resistant to contamination with pseudomonads should be selected for use in hospitals.

R B SMITH

Reckitt and Colman,
Pharmaceutical Division,

Phart

Brown, M R W, Resistance of Pseudomonas aeruginosa. London and New York, Wiley, 1975.

Lancet, 1970, 1, 1188 .

\section{Supervision of repeat prescribing}

SIR,-With reference to the letter from $\mathrm{Dr}$ D L Crombie and others (19 March, p 713) in reply to our article on "The need for supervision in the elderly receiving long-term prescribed medication" (28 February, p 505), contrary to their implied allegations, it must be stated that in no instance was the medication of any patient changed by either of the authors or any of the nursing staff assisting with the survey except after consultation with a member of the practice medical staff (or their locums) and at their direction.

Health Services Research Centre,

S M SHAW

Medical School,
University of Birmingham

\section{IUD and congenital malformation}

SIR, - We were interested to read the paper by Dr Herbert Barrie (28 February, p 488) of two cases of infants with limb reduction deformity born to mothers who were using copper-containing intrauterine contraceptive devices. We present a further case in which this association was observed.

The affected infant was born in 1975 to a 24 year-old Nigerian woman. The mother's first pregnancy in 1971 was legally aborted at eight weeks. In 1974 a Gravigard (Copper-7) IUD wa inserted, but she conceived in January 1975. The pregnancy was uneventful. At 37 weeks gestation the Copper-7 was partly extruded from the cervix and was easily removed. Two days later labour started spontaneously and the child was delivered normally. The male infant cried well at birth. It weighed $2820 \mathrm{~g}$ and the head circumference was $35 \mathrm{~cm}$. The child's head, face, trunk, and right upper limb were normal. The other limbs had severe reduction deformities. The left radius was absent and there were only two fingers on the left hand. Both lower limbs were abnormal: the left had a single slender long bone articulating with the foot, which was markedly dorsiflexed and had only two toes; on the right the femur was angulated, the fibula was absent, and only four metatarsals were present with four toes. The child has made satisfactory progress and gained $1 \mathrm{~kg}$ in the first three months.

The abnormalities described are more extensive than those described by Dr Barrie.
This infant will never achieve a normal gait, and will remain severely handicapped.

\section{P C LEIGHTON \\ D GLYN Evans} SHEILA M WALLIS

Department of Obstetrics and Paediatrics,

St Bartholomew's Hospital,

\section{Pets in hospitals}

SIR,-I was very interested in the article by Mr J E Cooper (20 March, p 698). Until recently insufficient attention had been paid to the role of pets in the treatment and care of patients. ${ }^{1}$ However, I would like to point to a problem which could arise if short-lived pets such as rodents or budgerigars were kept in hospital wards.

It has been suggested that one function of pets in childhood is to provide the child with an introduction to death as a natural process, ${ }^{2}$ but if a child has had sufficient contact with a pet in hospital to become identified with it, perhaps because of long or multiple admissions, then the death of the pet could give rise to much distress and anxiety. The pet has died in hospital and the child may already have anticipated such a fate for himself. This is the more likely if the pet chanced to have prodromal symptoms like those of the child's illness, such as coughing or shortness of breath in asthmatics. Also, if the child has had a hand in caring for the pet he may feel in part responsible for its death and experience considerable guilt. It might be argued that the same feelings would be present if a pet died in the child's home, but there the emotional support available to the child would usually be much greater than that available to him while in hospital.

I would agree with $\mathrm{Mr}$ Cooper, therefore, that pets in hospital can be of value, but I believe that the above factors should be borne in mind when selecting suitable pets, especially for units with a high proportion of longer-term patients. Incidentally, in Tayside at least, the problem is further compounded, as are all other problems relating to children's concept of hospitals, by parents who commonly explain to their children the disappearance of a sick or elderly pet by saying, "He's gone to the hospital."

Alasdair J MacDonald

Ninewells Hospital,

Dundee

Foote, N N, Marriage and Family Living, 1956, 18, Bossard, J H S, and Boll, E S, Sociology of Child Development. New York, Harper, 1966

Del Priore, C, The Child and the Pet. Talk to British Small Animal Veterinary Association, 3 October 1975 (unpublished).

SIR,-Mr J E Cooper's article on this subject (20 March, p 698) is important for paediatricians. There are several reasons why sick children may be helped by having an animal to watch, to caress, or to play with. From our earliest childhood animals are almost brothers. They are also models of mothers and fathers with which we can identify. And were not mammals and birds engaged in mothering and fathering long before man appeared on the scene of evolution? We took it from them. Animals have acted human roles in countless tales, fairy stories, and fables from the begin- 